\title{
N1c Stage Finding
}

National Cancer Institute

\section{Source}

National Cancer Institute. N1c Stage Finding. NCI Thesaurus. Code C48709.

A general term that refers to a TNM finding of cancer metastases usually in a limited number of regional lymph nodes. The definition of N1c TNM finding depends on the specific type of cancer that it refers to; for example, for breast cancer it refers to metastases in 1 to 3 axillary lymph nodes and in internal mammary lymph nodes with micrometastases or macrometastases detected by sentinel lymph node biopsy but not clinically detected; for colorectal cancer it refers to tumor deposit(s) in the subserosa, mesentery, or nonperitonealized pericolic or perirectal tissues without regional lymph node metastasis. 